\title{
TRAIAN LALESCU, SON OF CRAIOVA AND RECTOR OF THE POLITEHNICA SCHOOL OF TIMISOARA
}

\author{
Ioana Ionel*, Sabin Ionel, Ramon M. Balogh, \\ Delia Gabriela Calinoiu, and Nicolae D. Gherman
}

Politehnica University, Timisoara, 300006, Romania.

\section{Introduction}

In the history of mathematics in our country, Traian Lalescu is a creator of rare diversity, a great animator of his generation of mathematicians; a man equipped with great work capacity and sparkling intelligence, a gifted teacher with particularly pedagogical talent. His merits contributed to his professional development, as organiser and manager of new developed institutions. Among them, the coordination of the Politehnica School in Timisoara, as basic of the future Politehnica University of Timisoara, made him famous as well.

Traian Lalescu (1882-1929) was a Romanian academician and mathematician, university professor in Bucharest and Timisoara. Prominent personality of the Romanian mathematical school, he proved contributions to multiple fields of pure and applied mathematics. He is one of the founders of the theory of integral equations. He has left numerous studies in the areas of functional equations, trigonometric series, mathematical physics, geometry, algebra, mathematics history. He dealt in particular with the theory of integral equations and their application in solving some problems in the theory of differential equations, making important contributions in this field. He published the first treaty in the world on integral equations $[1,2,6]$.

Starting 1927, he suffered from pneumonia, which he tried to treat without success in Nice on the sunny coast of the Mediterranean. He died of pneumonia on June 15, 1929 in Bucharest, only at 47 years, and in full scientific power. To celebrate his personality, many high schools in the country bear the name "Traian Lalescu", and streets from Tîmisoara, Craiova, Resita, Oradea are called Traian Lalescu.

Since 1985 an inter-county competition has been organized for secondary and high school students in the counties of Arad, Caras-Severin, Hunedoara and Timis, called "Traian Lalescu". The fourth child, who had the same surname, Trajan, later became a symbolist poet, wrote, among other things, "I'm thinking about my father".

From 1990 Traian Lalescu became a post-mortem member of the Romanian Academy. In 2007, on the occasion of the 125th anniversary of the birth of Traian Lalescu, the Romanian Imprimeria issued a homage medal, and the "Curtea veche" publishing house lauched "Traian Lalescu - a name over the years", cared for by Smaranda Ecaterina Lalescu.

Some people assert their lives in one direction, usually related to their profession. Others are investing in scientific activities but also in activities that are immediately useful to the community. Some people enjoy the recognition of their fellows only for a while. Others have long appreciation only after being disappeared. Traian Lalescu was a complex man: a road opener, as a mathematician, a polytechnic school creator, a supporter of talented youth, and of sport, not at least as a man of culture.

\section{General Points}

\subsection{Biography Data and Studies}

Traian Lalescu was the son of a bank clerk, also called Traian Lalescu, with roots in Banat, from Cornea - Caraş-Severin County, who wrote "The Popular Bank Agenda and the Lalescu Coefficient Method". His mother was, after her parents, originated in Transylvania. The father's profession determined the family settle at different addresses, so that Traian's primary classes occurred in Bucharest, two high school classes in Craiova, then he finishes the gymnasium at Roman and the Iasi High School.

As a pupil, he was noted as a real talent in mathematics through his contribution to the Mathemati- 
cal Gazette (Gazeta matematica). In high school, as well as in gymnasium, Lalescu wan always the first prize of the class and received the school's honours (Lalescu was on the table of honor of the IASI gymnasium for example).

Even in the 6th grade of the lyceum (February 1898), Lalescu becomes a correspondent at Mathematical Gazette. His teacher, engineer Ion Ionescu, reports later on about Traian Lalescu that: "His entry among the correspondents Mathematical Gazette" occurred not as usual, shy, slow, progressive, but suddenly, intensely, at maximum possible speed and involvement. It was a unique case of appearing in the "Mathematical Gazette" of a prodigious activity of a young high school student $[2,3,4,5,6]$.

Although the situation of the family was quite modest, Traian Lalescu did not give up studies and he attended university courses in engineering and mathematics, always being the head of the promotion. He had the chance to study with famous professors, obtaining the "very good" rating. By 1900, he ranks first at the Bridges and Highways School in Bucharest. Also he studied at the Faculty of Sciences of the University of Bucharest, and in Iasi, where he had Gheorghe Ţiţeica, Spiru Haret, Ermil Pangrati, Anton Davidoglu and Nicolae Coculescu as professors and advisers. On June 17, 1903, he obtained his degree in Mathematics.

\subsection{Excellence in mathematics}

He received a scholarship from the philanthropist Vasile Adamachi to complete his studies in Europe. By 1905 he chose Paris to study and by 1908 he presented at Sorbonne his doctoral thesis entitled Sur l'equation de Volterra. This work will be considered the first outstanding contribution in the field of integral equations, and was written under the direction of Émile Picard. By 1911, he published Introduction to the Theory of Integral Equations, the first book ever on the subject of integral equations $[1,2,3]$.

During the First World War, following the occupation, the Romanian capital city moved to Iasi, which became the political and administrative centre of the country. The Mathematical Gazette was moved as well to Iasi, due to Traian Lalescu's devotion and en- thusiasm, due to Vasile Teodoreanu and other members of the editorial office, and thus continued to be printed and sent, even reaching the hands of subscribers in the front lines of the front $[4,5]$.

As reference work one indicates $[1,2]$ :

-"Introduction to the theory of integral equations" (1911);

- Le problème etnographique du Banat - (1919);

- Algebra Calculus - (1924);

- Polynomials. Rational fractions. Treatise of Analytical Geometry - (1925).

He obtained in Paris, as well, his engineer diploma at the Higher School of Electricity.

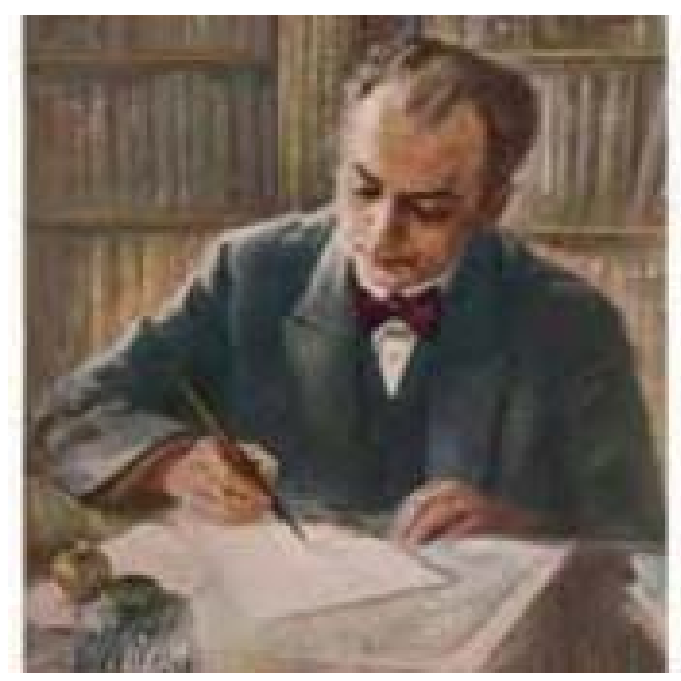

Figure 1. Traian Lalescu in his cabinet [6]

\subsection{Traian Vuia, the fighter for human rights.}

According to historical testimonies, by 1918 Bishop Caransebes, dr. Miron Cristea (1868-1939), met Traian Lalescu and have discussed the worrying situation of education in Romanian schools, statesponsored. By this opportunity a hierarch said, "one teaches teachers who do not know Romanian".

From the pulse of the ideas for the flowering of the Banat culture, initiated by Traian Lalescu and with the support of reputed patriots of Timisoara, a cultural patriotic association was founded and supported [7]. The general assembly of the association, in the context of its work, had uninterested support from priests and school servants. Being founded by representatives of the Church and of the school, 
the culture of the nation was raised. When it was to define the "Banat Cultural Association", Traian Lalescu said: "As a national society, the Association keeps the altar burning the fiery fire of our national unity". Concerned about the existing dramatic state, one convened a meeting in Caransebeş with the Banat teachers, the teachers in Mehedinţi and the school inspector there for August 1919. Following the evaluations made and the advanced ideas, in order to revitalize the Romanian education and to reorient the youth towards the national values, the establishment of the "Banat Cultural Association" (ACB), established by the famous theologist dr. Iosif Iuliu Olariu (1859- 1920).

The primary goal of the association was the collection of books for primary and especially secondary schools, from donations from authors, publishers, Bucharest School of Homes, Romanian Academy, people from over the mountains and purchases as well. Through the interventions of prof. dr. Traian Lalescu, deputy of Banat, the government offered in the first phase a million crowns to achieve the proposed objectives, involving the ministers of the time: Ionel I.C. Bratianu and C. Angelescu. In the first phase, the high schools from Caransebes, Timisoara, Lugoj, Orsova, Oravita and Lipova benefitted from these donated Romanian books. The "Light (Lumina)" from Orşova, the "Banat Court" in Caransebeş were also connected with the same purpose, and the example extended to many other cities $[7,8,9]$.

The results of the "Banat Cultural Association" action were overwhelming, since only in the first eight months, as the "Diocese sheet" had been distributed for free over 17, 000 books, over 600 volumes were given to the 12 secondary schools, each Teacher was offered free of charge "History of the Nation" and "Geography of Romania", and hundreds of students obtained free or at a low price important books.

Being very persistent and successful, Traian Lalescu organized an "university training system in the Banat, to temporarily fulfill the lack of a stable university", thanks to which in the important centers of Banat Nicolae Iorga, Onisifor Ghibu, Octa- vian Goga, Silviu Dragomir, Dimitrie Gusti, Dimitrie Onciu, Mihai Dragomirescu, Gheorghe Murnu, Virgil Madgearu, Vasile Pârvan, Traian Lalescu and others have lectured.

In 1919, in Paris, he published "Le problème etnographique du Banat", from which he remembered the patriotic spirit and his love for the Banat from which he came from the roots of his father: "The purpose of this work is precisely to help prevent the propagation of deceptive arguments, are more easily accepted by public opinion, the more they distort the truth" [7]. He was Deputy of the Caransebes county and general governor of the state budget for 1925 in the Brãtianu government [7].

\subsection{Traian Vuia, supporter}

Traian Lalescu's vision was beyond the limits of mathematics. He has generated a lifestyle, created models for the young people and future generations. Painting, drawing, singing in the cello, translating from Italian - all were hobbies and admired by him. He was a good friend with Tonitza, Medrea and Zamfiropol-Dall. For a few years he hosted a young student from Belgrade, Belle Arte, in whose talent he believed and gave him a room with his face to the sunrise to have light when he was painting: This was the later great painter, Corneliu Baba.

He had a real cult for the theater being a good friend to Victor Eftimiu, the Bulandra family, and not least to be mentioned of the artist Misu Fotino. In February 1916, at the initiative of a group of students and teachers from the capital, the University Club Bucharest was founded, afterwards the Students' Sport Club (Sportul studentesc), and Traian Lalescu was the first president. At that time, he was a member of the Central Committee of the governing body of Romanian sports. He also initiated the setting up of a sports group of the Polytechnic School in Timisoara [7].

\section{Traian Vuia, academic and first rector of the Politehnica School of Timisoara}

Practical spirit, Traian Lalescu was attracted by engineering. He worked for a while after 1912 as an assistant at the National School of Bridges and 
Roads, but in 1915 he followed an electricity course taught by Nicolae Vasilescu-Karpen, which he continued between 1918 and 1919 at the Upper School of Electricity in Paris.. In 1920 he persuaded the Ministry of Public Works to set up a Polytechnic School in Timisoara. The date of November 11, 1920 is the date of establishment of the Polytechnic School in Timisoara, which initially had two specialty departments: Electromechanics, namely Mines and Metallurgy, functioning with 15 teachers and 117 students [7].

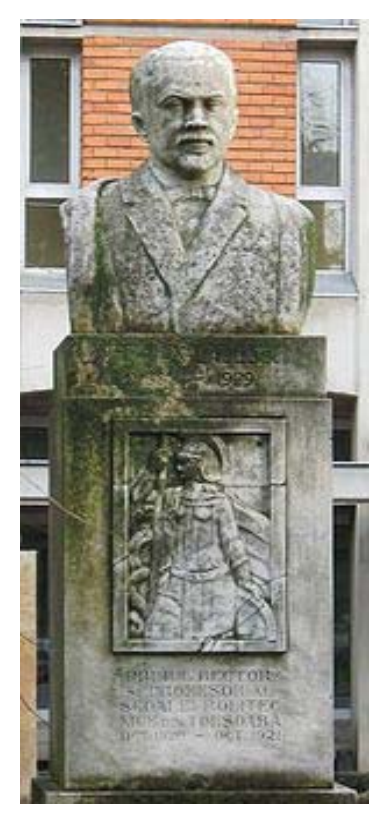

Figure 2. Traian Lalescu's bust realized by Corneliu Medrea, situated in front of the Faculty of Mechanical Engineering of the Politehnica University pg Timisoara (present name of the former Politehnica School of Timisoara).

On November 11, 1920, King Ferdinand signed the Royal Decree establishing the Polytechnic School of Timisoara, becoming the university center. Traian Lalescu strongly advocated the founding of this school and, together with Stan Vidrighin, he was a founding member of the Polytechnic School (Scoala Politehnica) in Timişoara [2, 3, 10]. As a rector, his first concern was to find the appropriate teachers. Traian Lalescu gave the students, at that time, the following services and lectures:

- In September 1921, for one year, the Machine
Elements (Organe de masini) course was taught by the university professor George Varisse of the Polytechnic School from Paris;

- He initiated a public lecture cycle, which helped to develop the students' intellectual education;

- He created for the students a special *assembly* according to the model at major European universities;

- Since the first year he has set up two laboratories: chemistry and physics;

- He also organized a series of school libraries, contributing to the development of the lecture pleasure, documentation capacity and studying culture among the students.

As a professor, Traian Lalescu became also directly deeply involved, he taught an impressive number of courses with extremely varied content, this being possible thanks to his travels in France and Germany where he deepened his teaching and teaching techniques.

\section{Conclusions}

Traian Lalescu is recognized as one of the founders of the theory of integral equations and the author of the first important mathematical synthesis of the universal scientific literature.

Traian Lalescu was a Romanian academician and mathematician, university professor in Bucharest and Timisoara. He founded the Polytechnic School of Timisoara and was his first rector.

Traian Lalescu's life was fully influenced by the diverse environment in which he was formed, thus:he was solid as the "Banatzan" (born in Banat), serious as the Transylvanian, lovingly beautiful as the Moldavian and with the spiraling spirit as all inhabitants of Bucharest.

Traian Lalescu is recognized and celebrated by posterity.

\section{Acknowledgment}

The article is dedicated by all authors to the memory of the outstanding academician Traian LALESCU, that not only conducted as first rector the Politehnica School of Timisoara, but also, introduced an unforgettable spirit in the high school system, in diverse fields, staring with mathematics, and 
this not only in theory, but also in practice. We hope to contribute by this way to promoting the present and future status of the Politehnica University of Timisoara, which is solid, linked and based on its past history.

Warm thanks are addressed to all authors' literature and sources, used in the article for references.

\section{References}

[1] https://en.m.wikipedia.org/wiki/Traian Lalescu\#Work

[2] http://www.pressalert.ro/2016/10

[3] Coleta de Sabata, Ioan Munteanu - Remember: Profesori ai Școlii Politehnice timișorene, Timișoara, Ed. Helicon, 1993.

[4] ***, Recreatii matematice, ei $\pi=-1$, Editura
“Recreaţii Matematice”, Iaşi, Anul VIII, Nr. 1

Ianuarie - Iunie, 2006.

[5] http://gheorghe.manolea.ro/2011/07/16/traianlalescu- $\%$ E2\%80\%93-matematician-ctitor-de-scoala-inginereasca/

[6] https://en.wikipedia.org/wiki/Traian_Lalescu

[7] http://www.observatorul.com/articles_main. asp?action $=$ articleviewdetail $\&$ ID $=11040$

[8] Conf. Vasile Petrica, 08 Septembrie 2010, http://ziarullumina.ro/tribune-ale-oamenilor-decultura-banateni-23096.html

[9] http://adevarul.ro/locale/timisoara/primelefacultati-timisoara-fost-cele-filosofie-drept-incepand-anul-1845-Scoala-politehnica-aparut-1920

[10] http://www.observatorul.com/articles_main. asp?action $=$ articleviewdetail $\&$ ID $=11040$ 